\title{
Demand side management in refrigeration applications
}

\author{
Alessia Arteconi ${ }^{1 *}$, Fabio Polonara ${ }^{2}$ \\ ${ }^{1}$ Università eCampus, via Isimbardi 10, 22060 Novedrate (CO), Italy \\ ${ }^{2}$ Dipartimento di Ingegneria Industriale e Scienze Matematiche, Università Politecnica delle \\ Marche, via Brecce Bianche 1, 60131 Ancona, Italy \\ Email: alessia.arteconi@uniecampus.it
}

\begin{abstract}
The refrigeration sector represents an important field of application for demand side management (DSM) strategies. For DSM are intended all those actions addressed to modify the final user's electricity consumption. Considering that refrigeration and air conditioning electricity consumption represent about $17 \%$ of the total electricity demand and taking into account the growing market of heat pumps, it is clear the central role of this sector for the implementation of management strategies on demand side. There are already several examples of feasible DSM technologies referred to refrigeration, including thermal energy storage systems, energy efficient devices or control systems by means of which the utility communicates with the final users. Purpose of this paper is to analyze the present state of the art in this field in order to categorize the applications (in terms of technology and range of temperature), list the existing implementation and provide a way to assess the potential flexibility provided to the power system. The results of this work are considered relevant to highlight the importance of refrigeration sector in such context and, thus, to boost the penetration of DSM strategies.
\end{abstract}

Keywords: Refrigeration, DSM, DR, Flexibility.

\section{INTRODUCTION}

Nowadays there is a growing interest towards the application of demand side management (DSM) strategies in the refrigeration sector due to the incidence on the overall energy consumption of refrigeration technologies. The International Institute of Refrigeration (IIR) estimates that the total number of refrigeration, air-conditioning and heat pump (HP) systems in operation worldwide is roughly 3 billion units and the refrigeration sector consumes about $17 \%$ of the overall electricity used worldwide [1]. About $45 \%$ of such consumption comes from the residential sector, that represents one of the main energy demanding sector in the world [1]. Indeed, buildings account for $40 \%$ of the total energy consumption in the European Union and in EU households, heating and hot water alone account for $79 \%$ of total final energy use (192.5 Mtoe) [2]. Cooling has a smaller share of total final energy use in Europe $(2-3 \%)$, but it has a growing trend. In particular, according to EIA (U.S. Energy Information Administration), the household electricity consumption is divided as shown in Figure 1, where about $50 \%$ of electricity is used for heating, cooling and refrigerators (i.e. refrigeration technologies) [3].

Also in industry heating (namely space and process heating) energy consumption has a considerable share: about $70.6 \%$, while cooling is $2.7 \%$ [2].

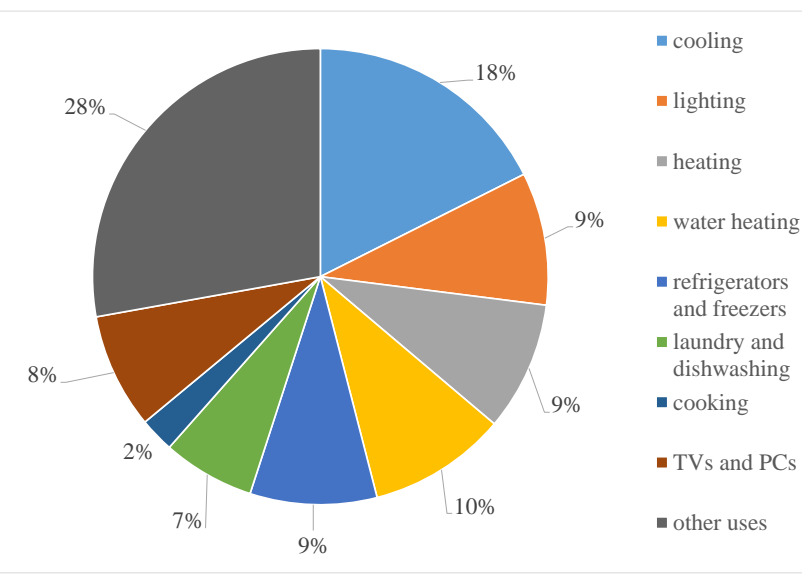

Figure 1. Household electricity consumption breakdown [3]

Considering the different sectors where refrigeration technologies can be applied, some average data about the worldwide electricity demand are provided in [1]. For example in supermarkets, $45 \%$ of the electric energy is used to cool cabinets and cold rooms for food storage, while household refrigerators and freezers consume almost $4 \%$ of residential electricity demand. In the latter sector, while the efficiency of the devices is growing, the number of units has been increasing constantly. Air conditioners, instead, are responsible in average for around $5 \%$ of global electricity consumption, with 
a variable percentage country by country (e.g. it is $14 \%$ in US and $40 \%$ in India). The relevance of heat pumps is also increasing, in 2015 about 800'000 units were sold in EU-21 and they allow $50 \%$ reduction of the building sector's $\mathrm{CO}_{2}$ emission [4].

Thus, the refrigeration sector needs to be accurately investigated to look for energy reduction and energy management strategies. Purpose of this work is to illustrate the potential for demand side management of refrigeration technologies. Both technologies and DSM strategies are categorized and main findings in literatures are illustrated Some useful indications for future research work are provided.

\section{METHODS}

In this work, first a definition of refrigeration technologies is provided and their classification on the basis of final use and temperature operative ranges. Then demand side management techniques are illustrated and a state of the art review of existing applications and potential of refrigeration technologies in the DSM context is reported. Eventually, flexibility indicators are described.

\subsection{Fields of application}

A refrigeration application is defined, for the purposes of this paper, as a system based on a reverse cycle (namely a simple reverse vapor compression cycle or its combinations, e.g. cascade cycles, two stage reverse cycles...) or a not-inkind technology (i.e. Brayton cycle, magnetic refrigeration, cryogenic stirling engine, sorption cycles, ejector cycles...). The refrigeration applications can be divided into several categories, depending on final use. According to IIR [1], they are: (i) refrigeration and food (i.e. domestic and commercial refrigeration and refrigerated transport); (ii) air conditioning; (iii) refrigeration and health; (iv) refrigeration in industry (i.e. liquefied natural gas, LNG); (v) heat pumps; (vi) leisure and sport. In Figure 2 the share of units in operation for each category is shown.

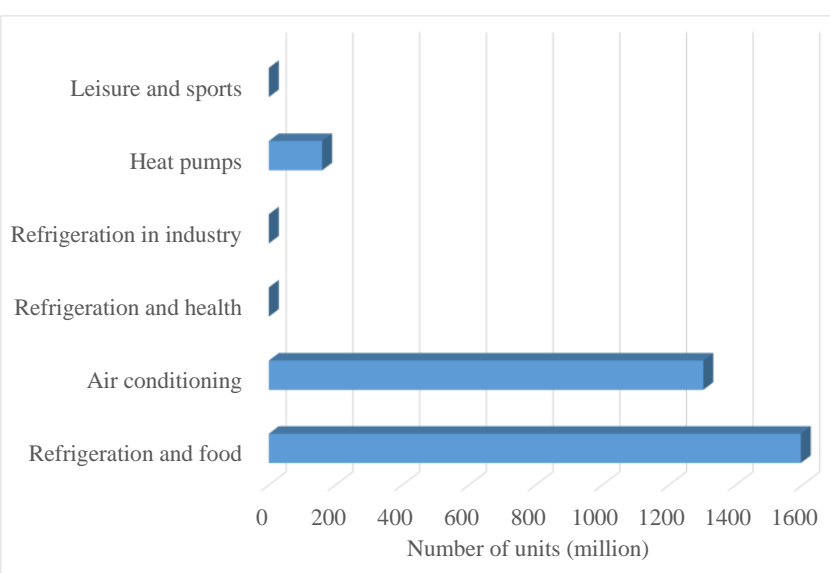

Figure 2. Number of refrigeration systems in operation worldwide per application [1].

Among such categories, in this work, the most interesting are considered and classified on their operating temperature range as follows:

- Air conditioning $\left(\mathrm{T}=0 \div 15^{\circ} \mathrm{C}\right)$, space heating $\left(\mathrm{T}=25 \div 60^{\circ} \mathrm{C}\right)$ and domestic hot water production $\left(\mathrm{T}=45 \div 65^{\circ} \mathrm{C}\right)$ in residential or commercial buildings, performed by means of chillers and heat pumps respectively;

- Household refrigerators $\left(\mathrm{T}=-20 \div 3{ }^{\circ} \mathrm{C}\right)$;

- Supermarkets $\left(\mathrm{T}=-20 \div 3^{\circ} \mathrm{C}\right)$ and refrigerated warehouses $\left(\mathrm{T}=-20 \div 13^{\circ} \mathrm{C}\right.$, depending on the food stored).

\subsection{Demand side management}

DSM are all those actions addressed to modify the final user's electricity consumption. DSM strategies mainly are divided into three different categories: (i) energy-efficient enduse devices; (ii) additional equipment, systems and controls to enable load shaping (e.g. energy storage); (iii) communication systems between end-users and external parties, e.g. demand response (DR) [5]. While the first point concerns energy conservation by means of devices using less energy, the other two points deal with systems aimed at modifying the final user demand profile: thermal energy storage systems can be used to store surplus energy to be released for a later use, whereas demand response achieves changes in final users load by means of price signals from the grid.

\section{DSM IN REFRIGERATION}

In this section, how demand side management can be realized in the refrigeration sector is illustrated. All the refrigeration applications here considered (i.e. chiller and heat pumps; domestic refrigerators; supermarkets and refrigerated warehouses) belong to the category of thermostatically controlled loads, they are aimed at keeping the operative temperature in a given range and they allow to shift thermal loads produced by electricity conversion, thanks to inherent or external thermal energy storages. The results are divided on the basis of the above-mentioned categorization of DSM realizations: energy efficiency, energy storage, demand response.

\subsection{Chillers and heat pumps}

\subsubsection{Energy efficiency}

Energy efficiency in reverse cycle devices can be achieved in several ways. It is possible to act on: (i) the choice of a proper and environmental friendly refrigerant; (ii) more efficient design of components (VFR, ejectors....); (iii) application of not-in-kind technologies; (iv) optimization of the overall HVAC (heating ventilation and air conditioning) system and control strategies.

\subsubsection{Energy storage}

The relevance of coupling reverse cycle devices (i.e. chillers and heat pumps) with thermal energy storages in order to modify the final user demand and match it with the power system production has been demonstrated in literature [6].

As far as cold applications are concerned, a cold thermal energy storage (CTES) is typically coupled to a chiller for air conditioning. It can be a thermally stratified chilled water storage (sensible TES) or an ice storage (latent TES). The purpose of using a TES is to improve refrigeration equipment efficiency, reduce the installed capacity, increase the operational flexibility and reduce energy costs: cold is produced during off-peak periods and used during on-peak periods. Typical operational strategies of such systems are: full storage and partial storage strategies (Figure 3) [7]. A full 
storage strategy shifts the entire peak cooling load to off-peak hours. In a partial storage strategy, the load is partially supplied by the thermal storage and partially by the refrigeration unit. The chiller can be designed to operate as load levelling (Figure 3B) or demand limiting (Figure 3C). Partial storage is the most used configuration because of lower initial capital costs. It saves about $40-60 \%$ of peak cooling electricity demand. Full storage is interesting for short peak periods with very high costs for electricity production. The peak electricity demand can be reduced up to $80-90 \%$ [8]. In the same way, thermal energy storage systems can be used together with heat pumps for implementing demand side management strategies [9], such as peak shaving or night load shifting. These kind of applications can lead to energy bill reductions, even if generally the energy consumption increases because of thermal losses in the storage systems.
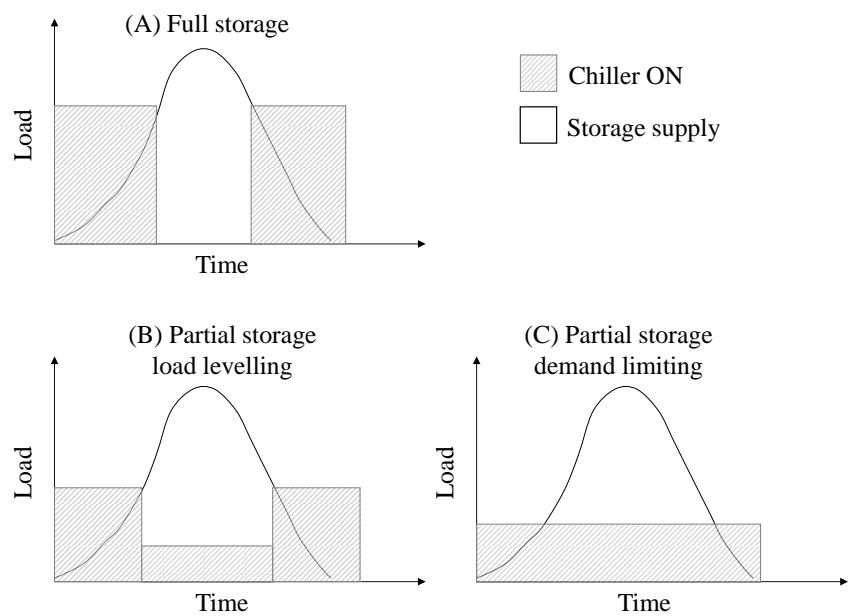

Figure 3. CTES operational strategies [13].

In alternative to the use of external storage tanks, also much more effective in buildings, thermal storage can be provided by the use of the building envelop thermal mass as passive or active energy storage [10]. It is considered active thermal storage e.g. the floor heating or TABs (thermally activated buildings) [11]: the floor is a large low temperature radiating surface while the concrete acts like a thermal storage heated by air, water or directly by electric resistances. The passive thermal storage due to the building envelope can be easily exploited by means of variable temperature set points, that can be adjusted in a certain range in order to keep the internal comfort and at the same time provide useful flexibility to the power system [12]. Moreover, PCM can be integrated within the building components and used passively, for precooling/heating and for reducing the thermal load request, or alternatively actively by charging and discharging them on the basis of a given strategy.

\subsubsection{Demand response}

Among the other devices, heat pumps are recognized as systems to be effectively used to implement demand response strategies in the smart grid. They are mainly aimed at three different purposes: (i) provision of ancillary services for the power grid, (ii) renewable energy sources (RES) integration, (iii) energy bill reduction for the final user [13].

(1) Ancillary services contain: voltage control, congestion management and provision of spinning and non-spinning reserve [13]. In voltage control applications heat pumps load is modified to guarantee that the distribution network voltage is maintained within the allowed limits: HP active power demand is decreased in times of local under-voltage and increased in times of over-voltage. The latter case can happen for example in presence of photovoltaic (PV) panels, feeding electricity in the grid. [14] demonstrates the positive role of heat pumps to reduce curtailment of electricity from PV panels. As far as congestion management in the distribution grid is concerned, heat pumps must be operated in an optimized scheduling and power rating in order to avoid limitations in the transformer and line capacity [13]. Eventually heat pumps can serve as spinning and non-spinning reserves used by the transmission system operator (TSO), i.e. as reserve capacity that can be regulated downward or upward to match demand and supply. Different strategies can be implemented with these reserves, such as peak clipping or valley filling.

(2) Another important role played by heat pumps and the flexibility they provide, is related with the possibility to integrate renewable energy sources both at building level and at power system level. Mainly the RES considered are wind and PV. The work [15] shows how heat pumps coupled with thermal storage can increase the selfconsumption of PV electricity production in an industrial building. In this study, the tank operative conditions are analyzed in order to find the best configuration: up to $80 \%$ of PV electricity can be used to cover the thermal demand coming from the building.

(3) Regarding energy bill reduction, electricity price signals are used to influence the final users' consumption pattern. Mainly there are two types of tariff structures: Time of Use (TOU) tariffs, when they vary depending on the period of the day, and Real Time Pricing (RTP), that, instead, change continuously based on the electricity market price [16]. In this context, the heat pump demand can be adjusted with the intent of reducing electricity costs, improving the system performance, increasing RES integration or improving power system benefits (i.e. reducing total operational costs). It is evident how the final users and power system interests are strictly related.

\subsection{Household refrigerators}

\subsubsection{Energy efficiency}

Increasing the energy efficiency of these devices acts on power systems energy conservation. There are different aspects to be addressed in order to increase a refrigerator performance, mainly: (i) compressors efficiency, (ii) thermal insulation and (iii) enhancement of heat exchangers heat transfer [17]. Compressor efficiency has a central role because almost $80 \%$ of refrigerators energy consumption comes from the compressor. In this sense, variable speed compressors and linear compressors have been considered to replace standard ON/OFF compressors, even if they still represent expensive solutions. As far as the thermal insulation is concerned, generally polyurethane boards are used, but they can be substituted by vacuum insulation panels (VIPs), four times more resistant to heat transfer. The last category of interventions about heat exchangers heat transfer enhancement includes: addition of a liquid-to-suction line heat exchanger; application of loop heat pipe evaporator; application of micro- 
fins in condenser and evaporator and application of phase change materials [17]. The last point is further discussed in section 3.2.2.

\subsubsection{Energy storage}

There are several studies that deal with the use of phase change materials in refrigerators to enhance their performance. PCM at the evaporator side is the case more often investigated. Mainly, PCM reduces the ON time of the compressor, maintains a more stable temperature, thus guarantees a better food quality, also in case of power outages. Instead, using PCM at condenser can extend condenser heat rejection process also during compressor OFF time, then achieving lower condensation temperature [17].

Paper [18] investigates the role of PCM for reducing energy consumption in domestic refrigerators (about 12\%). Moreover, it is shown that the presence of PCM helps in reducing the temperature fluctuations in the cold chamber. Eventually, thanks to PCM, the load can be increased (for a period of 0.6 h) or decreased (for a period of 1.8h) for DSM purposes, while maintaining the temperature in the allowed range.

\subsubsection{Demand response}

There are about 1.5 billion domestic refrigerators and freezers in service worldwide, which consume $4 \%$ of the total electricity production [1]. Thus, it is highly relevant to consider DR in this sector. A refrigerator is a cool chamber, where a reverse cycle is activated by an internal thermostat to maintain the temperature in a fixed range. The inside temperature is influenced by (i) external heat gains; (ii) door openings; (iii) heat in the stored food [19]. The thermal capacity of the internal air and of the walls (where also phase change materials can be encapsulated to further increase it) provide the thermal inertia of this system that influences its possibility to modify the electrical load.

In [20] the possibility to use thermal storage of electrical household refrigerators as balancing power is explored. They develop a model to aggregate the demand of 5000 refrigerators, two types of control signals are applied. Results show that the control signal affects the obtainable load shape and confirm the suitability of these loads to be shifted easily and used as short-term reserves (15 min). In [19] different DR strategies are applied to domestic refrigerators. This paper shows the importance of desynchronizing the operation of a group of refrigerators in order to limit the payback load after the DR event that could cause severe peak power demand. The issue of synchronization is also shown in [21], where a frequency based demand side management strategy is applied to a cluster of refrigerators. [22] illustrates a strategy to manage at large scale the load of domestic refrigerators in order to reduce peak energy demand. They demonstrate that their strategies (acting on switching ON/OFF periods or temperature bounds) can also improve losses issue and voltage profile of power distribution systems. Paper [23] develops a gray-box model for a refrigerator, identified by means of experimental data, to be used in model predictive controls aimed at shifting the refrigerator load for DR purposes. This kind of modelling approach is also useful for Home Energy Management System (HEMS), as proposed in the work [24] that develops a system for executing DR autonomously.

\subsection{Supermarkets and refrigerated warehouses}

\subsubsection{Energy efficiency}

In supermarkets, a large part of the energy consumption comes from refrigeration systems (that can be stand-alone, condensing units and centralized [25]), it is due to compressors work and is mainly influenced by (i) the amount of heat gained in cabinets (that depends on cabinet temperature requirement, rate of product replacement, cabinet aisle temperature, indoor humidity); (ii) the rate of heat rejected at condensers (that depends on the surface area of the condensers, the rate of air flow and outdoor air temperature) [26]. Moreover, there is often a lack of energy awareness and communication among facility managers, maintenance team and store staff that makes many supermarkets perform poorly in terms of energy efficiency [26]. [26] defines an energy performance indicator, $\mathrm{Eq}(1)$, to quantify the energy consumption of a supermarket on the basis of the most relevant parameters: compressors power demand, store opening hours and cooling degree days (CDD):

$$
C=\frac{E_{A}}{C I \times O H \times C D D_{n}}
$$

where $E_{A}$ is the annual refrigeration energy consumption $(\mathrm{kWh})$, normalized with respect to:

- CI $(\mathrm{kW})$ : aggregated connected load of the refrigeration system;

- $\mathrm{OH}=1+(\mathrm{H}-14) \mathrm{x} 0.94 \%$ : it depends on the weekdays opening hours, $\mathrm{H}$;

- $\mathrm{CCDn}=1+(\mathrm{CCD}-20.1) \times 2.8 \%$ : it depends on the annual average cooling degree days.

Paper [27] proposes to disaggregate the energy consumption of supermarket store into weather-dependent and weather-independent loads. They show that weatherindependent loads (lights, computers...) can contribute up to $45-77 \%$ of a store total electricity consumption, while refrigeration loads weight more than cooling loads, thus occupancy in the supermarket has a minor role. Moreover, some studies have demonstrated that integrating HVAC and refrigeration in a supermarket can lead to reductions in energy consumption. In supermarkets, there are normally vapor compression cycles operating at three different temperature levels, corresponding to air conditioning units, medium and low temperature refrigeration plants respectively, thus it is possible to organize the systems according to a cascade layout [28]. Research results show that the use of natural refrigerants, e.g. $\mathrm{CO}_{2}$ transcritical cycles with ejectors, is a good option for energy efficient and sustainable solutions in this field [28].

\subsubsection{Energy storage}

Some studies have also investigated the role of thermal storage in industrial refrigeration.

Paper [29] analyzes the case of a refrigerated warehouse where the stored frozen food is used as passive thermal storage by allowing a $5^{\circ} \mathrm{C}$ temperature increase (the food quality is not altered because the temperature is always $<-18^{\circ} \mathrm{C}$ ). It is shown that when a limited load strategy, that shifts partially the electrical load during night off peak periods, is applied to the warehouse, about $50 \%$ of energy cost saving is achieved. 
Paper [30] proposes to supply refrigerated warehouses by means of renewable energy sources coupled with cryogenic energy storage systems. Such storage systems use the RES surplus electricity to liquefy and store liquid air. The liquid air, when the RES production is too low, can be vaporized, thus the cooling load is used to cool the warehouse, while the air is expanded in turbines for power generation.

\subsubsection{Demand response}

The work [31] studies possible control strategies for aggregation of supermarkets electricity demand to balance demand and supply side of the power system. The supermarkets flexibility is due to the possibility of pre-cooling the contained foodstuff. It is demonstrated that also with a simple control strategy without any kind of optimization it is possible to realize an upward regulation of $900 \mathrm{~kW}$ within 15 minutes during peak times.

Paper [32] describes a novel economic-optimizing model predictive control scheme to reduce supermarkets operating costs. The flexibility provided by their refrigeration systems is used as ancillary reserve in the power grid and can lead up to $70 \%$ cost reduction.

\section{FLEXIBILITY PROVIDED BY REFRIGERATION}

Flexibility provided by a refrigeration application is intended as the power consumption deviation of the device from its optimal value to a new profile aimed at compensating power imbalances in the grid. Such new load pattern can be obtained by using heat buffers where heat/cold can be stored when there is a surplus of electricity available and vice-versa. Heat buffers are mainly represented by thermal energy storages and building thermal mass.

There are several studies in literature that have proposed a way to quantify this flexibility, in particular it is possible to measure it as hourly (h) load shed (LS) potential of a device with respect to its rated power consumption ( $\left.\mathrm{P}^{\text {base }}\right), \mathrm{Eq}(2)[12]$ :

$$
L S=\frac{P_{h}^{\text {base }}-P_{h}^{L S}}{P_{h}^{\text {base }}}
$$

Among the others, the hourly load shed potential is a good indicator to quantify the flexibility provided by refrigeration systems when e.g. their dynamic operation is analyzed during DR events or in case of improved efficiency, because it is simple to be implemented and effective.

\section{CONCLUSIONS}

In this work, a study of demand side management strategies applied to the refrigeration sector is provided. The interest towards this sector for DSM purposes has been demonstrated by the analysis of electricity consumption in such field. The main refrigeration applications have been considered separately (chillers and heat pumps for HVAC in buildings; household refrigerators; supermarkets and refrigerated warehouses in the industrial sector) with reference to the different DSM realizations (energy efficient devices; energy storage; DR). Possible ways to assess the energy flexibility provided by refrigeration technologies adhering to DSM strategies are discussed. Starting from the presented framework it will be possible to develop future works to quantify the DSM potential (i.e. flexibility) in specific real refrigeration applications.

\section{ACKNOWLEDGMENT}

This work has been supported by MIUR of Italy in the framework of PRIN2015 project: "Clean heating and cooling technologies for an energy efficient smart grid", Prot. 2015M8S2PA.

\section{REFERENCES}

[1] Coulomb D., Dupont J.L., Pichard A. (2015). The role of refrigeration industry in the global economy, International Institute of Refrigeration, Paris, France, Report No. 29th Informatory Note on Refrigeration Technology.

[2] European Commission, Energy - Heating and cooling, from https:/lec.europa.eu/energy/en/topics/energyefficiency/heating-and-cooling, accessed on 22 August 2017.

[3] U.S. Energy Information Administration. (2017). Annual energy outlook, Washinghton, U.S., Report No AEO2017.

[4] Thomas N., Pascal W. (2015). European heat pump market and statistics report 2015, Technical report, The European Heat Pump Association AISBL (EHPA), Brussels.

[5] Gellings C.W. (2009). Enabling Energy Efficiency and Demand Response, The Smart Grid, The Fairmont Press, Lilburn, pp. 134-141.

[6] Arteconi A., Hewitt N.J., Polonara F. (2012). State of the art of thermal storage for demand side management, App. Energy, Vol. 93, pp. 371-389. DOI: 10.1016/j.apenergy.2011.12.045

[7] Dincer I., Rosen M.A. (2011). Thermal energy storage: Systems and applications, Second edition, Wiley.

[8] Hasnain S.M. (1998). Review on sustainable thermal energy storage technologies, Part 2: Cool thermal storage, Energy Convers Manag, Vol. 39, pp. 11391153. DOI: $10.1016 / \mathrm{S} 0196-8904(98) 00024-7$

[9] Arteconi A., Hewitt N.J., Polonara F. (2013). Domestic demand-side management (DSM): Role of heat pumps and thermal energy storage (TES) systems, App. Therm. Eng., Vol. 51, pp. 155-165. DOI: 10.1016/j.applthermaleng.2012.09.023

[10] Zhang Y., Zhou G., Lin K., Zhang Q., Di H. (2007). Application of latent heat thermal energy storage in buildings: State-of-the-art and outlook, Build Environ, Vol. 42, pp. 2197-2209. DOI: 10.1016/j.buildenv.2006.07.023

[11] Arteconi A., Costola D., Hoes P., Hensen J.L.M. (2014) Analysis of control strategies for thermally activated building systems under demand side management mechanisms, Energy Build., Vol. 80, pp. 384-393. DOI: 10.1016/j.enbuild.2014.05.053

[12] Yin R., Kara E.C., Li Y., DeForest N., Wang K., Yong T., Stadler M. (2016). Quantifying flexibility of commercial and residential loads for demand response 
using setpoint changes, App. Energy, Vol. 177, pp. 149164. DOI: $10.1016 /$ j.apenergy.2016.05.090

[13] Fischer D., Madani H. (2017). On heat pumps in smart grids: A review, Renew. Sustain. Energy Rev., Vol. 70, pp. 342-357. DOI: $10.1016 /$ j.rser.2016.11.182

[14] Baetens R., De Coninck R., Van Roy J., Verbruggen B., Driesen J., Helsen L., Saelens D. (2012). Assessing electrical bottlenecks at feeder level for residential net zero-energy buildings by integrated system simulation, App. Energy, Vol. 96, pp. 74-83. DOI: 10.1016/j.apenergy.2011.12.098

[15] Arteconi A., Ciarrocchi E., Pan Q., Carducci F., Comodi G., Polonara F., Wang R. (2016). Thermal energy storage coupled with PV panels for demand side management of industrial building cooling loads, App. Energy, Vol. 185, pp. 1984-1993. DOI: $\underline{10.1016 / \text { j.apenergy.2016.01.025 }}$

[16] Shen B., Ghatikar G., Lei Z., Li J., Wikler G., Martin P. (2014). The role of regulatory reforms, market changes, and technology development to make demand response a viable resource in meeting energy challenges, App. Energy, Vol. 130, pp. 814-823. DOI: 10.1016/j.apenergy.2013.12.069

[17] Joybari M.M., Haghighat F., Moffat J., Sra P. (2015). Heat and cold storage using phase change materials in domestic refrigeration systems: The state-of-the-art review, Energy Build., Vol. 106, pp. 111-124. DOI: 10.1016/j.enbuild.2015.06.016

[18] Sonnenrein G., Baumhögger E., Elsner A., Fieback K., Morbach A., Paul A., Vrabec J. (2015). Copolymerbound phase change materials for household refrigerating appliances: experimental investigation of power consumption, temperature distribution and demand side management potential, Int. J. Refrig., Vol. 60, pp. 166-173. DOI: $\underline{10.1016 / \text { j.ijrefrig.2015.06.030 }}$

[19] Lakshmanan V., Marinelli M., Kosek A.M., Nørgård P.B., Bindner H.W. (2016). Impact of thermostatically controlled loads' demand response activation on aggregated power: A field experiment, Energy, Vol. 94, pp. 705-714. DOI: $10.1016 /$ j.energy.2015.11.050

[20] Stadler M., Krause W., Sonnenschein M., Vogel U. (2009). Modelling and evaluation of control schemes for enhancing load shift of electricity demand for cooling devices, Environ. Model. Soft., Vol. 24, pp. 285-295. DOI: $10.1016 /$ j.envsoft.2008.07.003

[21] Kremers E., Gonzalez de Durana J.M., Barambones O. (2013). Emergent synchronization properties of a refrigerator demand side management system, Appl. Energy, Vol. 101, pp. 709-717. DOI: 10.1016/j.apenergy.2012.07.021.

[22] Niroa G., Salles D., Alcântarab M.V.P., da Silva L.C.P. (2013). Large-scale control of domestic refrigerators for demand peak reduction in distribution systems, Elect. Power Syst. Res., Vol. 100, pp. 34-42.
[23] Sossan F., Lakshmanan V., Costanzo G.T., Marinelli M., Douglass P.J., Bindner H. (2016). Grey-box modelling of a household refrigeration unit using time series data in application to demand side management, Sustain. Energy, Grids Net., Vol. 5, pp. 1-12. DOI: 10.1016/j.segan.2015.10.003

[24] Shakeri M., Shayestegan M., Abunima H., Reza S.M. S., Akhtaruzzaman M., Alamoud A.R.M., Sopian K., Amin N. (2017). An intelligent system architecture in home energy management systems (HEMS) for efficient demand response in smart grid, Energy Build., Vol. 138, pp. 154-164. DOI: 10.1016/i.enbuild.2016.12.026

[25] Mylona Z., Kolokotroni M., Tassou S.A. (2017). Frozen food retail: measuring and modelling energy use and space environmental systems in an operational supermarket, Energy Build., Vol 144, pp. 129-143. DOI 10.1016/j.enbuild.2017.03.049

[26] Acha S., Du Y., Shah N. (2016). Enhancing energy efficiency in supermarket refrigeration systems through a robust energy performance indicator, Int. J. Refrig., Vol. 64, pp. 40-50. DOI: 10.1016/j.ijrefrig.2015.12.003

[27] Iyer S.R., Sankar M., Ramakrishna P.V., Sarangan V., Vasan A., Sivasubramaniam A. (2015). Energy disaggregation analysis of a supermarket chain using a facility-model, Energy Buld., Vol. 97, pp. 65-76. DOI: 10.1016/j.enbuild.2015.03.053

[28] Cecchinato L., Corradi M., Minetto S. (2012). Energy performance of supermarket refrigeration and air conditioning integrated systems working with natural refrigerants, Appl. Therm. Eng., Vol. 48, pp. 378-391.

[29] Altwies J.E., Rendl D.T. (2001). Passive thermal energy storage in refrigerated warehouses. Int. $J$. Refrig., Vol. 24, pp. 149-157. DOI: 10.1016/S01407007(00)00080-3

[30] Fikiin K., Stankov B., Evans J., Maidment G., Foster A., Brown T., Radcliffe J., Youbi-Idrissi M., Alford A., Varga L., Alvarez G., Ivanov I.E., Bond C., Colombo I., Garcia-Naveda G., Ivanov I., Hattori K., Umeki D., Bojkov T., Kaloyanov N., (2017). Refrigerated warehouses as intelligent hubs to integrate renewable energy in industrial food refrigeration and to enhance power grid sustainability, Trends Food Sci. Tech., Vol. 60, pp. 96-103. DOI: 10.1016/j.tifs.2016.11.011

[31] Pedersen R., Schwensen J., Biegel B., Stoustrup J., Green T. (2014). Aggregation and control of supermarket refrigeration systems in a smart grid, Proc. 19th World Cong. Int. Feder. Autom. Contr., Cape Town, South Africa.

[32] Hovgaard T.G., Larsen L.F.S., Edlund K., Jørgensen J.B. (2012). Model predictive control technologies for efficient and flexible power consumption in refrigeration systems, Energy, Vol. 44, pp. 105-116. DOI: $\underline{10.1016 / \text { j.energy.2011.12.007 }}$ 